\title{
Amino Acids during Perioperative Period
}

\author{
Takeshi Yokoyama ${ }^{1 *}$, Ippei Yamaoka ${ }^{2}$, Takashi Hitosugi ${ }^{1}$, Eva Selldén $^{3}$ \\ ${ }^{1}$ Department of Dental Anesthesiology, Faculty of Dental Science, Kyushu University, Fukuoka, Japan \\ ${ }^{2}$ Medical Foods Research Institute, OS-1 Division, Otsuka Pharmaceutical Factory Inc., Naruto, Japan \\ ${ }^{3}$ Anestesi-, Operations-och Intensivvårdskliniken, Karolinska Universitetssjukhuset Solna, Stockholm, Sweden \\ Email: ^yokoyama@dent.kyushu-u.ac.jp
}

How to cite this paper: Yokoyama, T., Yamaoka, I., Hitosugi, T. and Selldén, E. (2017) Amino Acids during Perioperative Period. Open Journal of Anesthesiology, 7, 287-295.

https://doi.org/10.4236/ojanes.2017.79029

Received: August 8, 2017

Accepted: September 18, 2017

Published: September 22, 2017

Copyright (c) 2017 by authors and Scientific Research Publishing Inc. This work is licensed under the Creative Commons Attribution International License (CC BY 4.0).

http://creativecommons.org/licenses/by/4.0/

\begin{abstract}
During anesthesia, thermoregulation is impaired and hypothermia will frequently occur in most patients. Hypothermia affects immunologic activity, bleeding tendency and the recovery from anesthesia. Therefore, it may prolong hospital stay, and increase morbidity, e.g. surgical site infections, cardiac events and multiple organ dysfunctions in trauma. External warming is often used to prevent hypothermia. However, infusion of amino acids is also valuable to prevent hypothermia due to their enhanced thermogenic action under anesthesia. During surgery, amino acids administration would maintain the body homeostasis, and counteract the disadvantageous fasting metabolism. Postoperatively, amino acids may be advantageous for the healing of the surgical wound. Thus, appropriate nutritional management, including glucose, during the perioperative period would prevent catabolism, frequently occurring after surgery. Protocols like ERAS (Enhanced Recovery After Surgery) are proposed for quick recovery after surgery. ERAS protocol recommends preoperative carbohydrate and early enteral nutrition, but does not include infusion of amino acids during the perioperative period. During prolonged surgery, patients clearly need good nutritional support. In this article, we intend to describe the problems of hypothermia briefly, and explain the mechanism of amino acids in hypothermia prevention. In addition, we address some evidences of nutritional management during the perioperative period.
\end{abstract}

\section{Keywords}

Anesthesia, Hypothermia, Amino Acids, Nutrition

\section{Introduction}

During the perioperative period, hypothermia initiates adverse events, which could lead to poor outcome after surgery [1] [2] [3]. Administration of amino 
acids during the perioperative period has been demonstrated to prevent hypothermia during anesthesia [4]. In addition, amino acids may be important to optimize perioperative nutritional management. In this point, amino acids may be related to the enhanced recovery.

\section{Hypothermia during Surgery}

Core temperature is maintained at around 37 degree centigrade, via a delicate and thoroughly controlled system, including both central and peripheral components [5]. However, sympathetic nerve function is usually suppressed during general anesthesia and even, to some extent, during spinal anesthesia [6] [7].

Hypothermia during anesthesia is caused by decreased heat production as well as increased heat loss and impaired hypothalamic thermoregulation [8]. Body heat redistribution between core and peripheral tissues would also contribute. Specifically, inadvertent hypothermia consists of 3 phases [9] [10]. Finally, temperature may reach to a stagnant phase at low degree. Room temperature, evaporation from the surgical field, and cold infusion would have additive effect on hypothermia. Specific heat capacity of human body is $0.83 \mathrm{kcal} / \mathrm{kg}$, and specific heat capacity of infusion solution and blood transfusion preparation is around $1.0 \mathrm{kcal} / \mathrm{kg}$ [11]. $50 \mathrm{kcal}$ of heat loss, which correspond to around 4 litre of infusion at 25 degree centigrade, decreases body temperature by around 1 degree centigrade.

\section{Problems and Benefits of Hypothermia}

Hypothermia often causes shivering after anesthesia, which may increase oxygen consumption 3 to 4 times, and increases the risk of ventricular tachycardia and morbid cardiac events [1]. There is a report that body cooling might cause decreased oxygen pressure in the brain tissue when shivering started [12]. Hypothermia prolongs recovery from anesthesia due to decrease in minimum alveolar concentration of inhalation anesthetics, and due to prolonged recovery of muscle relaxants [13].

Hypothermia reduces platelet function and impairs enzymatic reaction of the coagulation cascade, which increases blood loss during surgery and the risk of transfusion [14] [15] [16].

Hypothermia would promote surgical infection and delay wound healing, most likely due to decreased subcutaneous oxygen tension [17], and impaired immune function. Warming patients before surgery reduces the risk of surgical infection [18]. Hypothermia may be associated with increased morbidity and mortality after major surgery [19].

On the other hand, hypothermia may be protective in the brain tissue during oxygen deficiency [20], since brain metabolism and thus oxygen consumption decreases along with the temperature. Metabolic rate in the brain decreases by 6 to $7 \%$ by every 1 degree centigrade decrease in the body temperature [21]. Besides, hypothermia had an additive effect with barbiturate for brain protection [22]. 


\section{Prevention of Hypothermia}

Active warming systems, for example forced-air warming blowers and infusion fluid warming devices, are frequently used to prevent hypothermia in the operation room. In the case of forced-air warming blower, however, a risk of low temperature burn injury is reported [23]. In addition, it is questioned whether it may increase the risk of bacterial pollution of the surgical field [24]. When a large volume of infusion is required, infusion fluid warming devices are useful. However, they might be less effective at low infusion speed.

Mizobe et al. reported that fructose infusion is useful for avoiding hypothermia [25]. It requires $2.0 \mathrm{~g} / \mathrm{kg}$ of fructose for 4 hours. However, it has been pointed out for a long time that equivalent dose of fructose infusion may decrease ATP in the liver possibly leading to hepatic damage [26]. In addition, fructose infusion would cause acidosis and hyperuricemia. Fructose infusion, therefore, should be avoided during perioperative period.

Selldén, one of authors of this article, reported that infusion of amino acids before or during general anesthesia is useful to prevent hypothermia [27]. In addition, amino acids infusion was demonstrated to shorten hospital stay [2]. Kasai reported that infusion of amino acids is useful to prevent hypothermia not only during general anesthesia but also during spinal anesthesia [6] [7]. Osmotic pressure of amino acids solution is very high, and rapid infusion may cause phlebitis and imbalance of serum electrolytes. Clinically, however, slow infusion, around $240 \mathrm{~kJ} / \mathrm{h}$, preferably in a central venous line, for a few hours usually cause no problems. This method is convenient and has additive effect with other warming systems.

\section{Metabolism of Amino Acids}

The methodology using amino acids is simple in that it stimulates internal heat production in the body, compared to heating techniques heavily depending on medical devices. The metabolic fate of the infused amino acids falls roughly into two categories: oxidation for energy production and/or building blocks for protein synthesis. Irrespective of pathway, large amounts of energy are required for amino acid metabolism, and eventually heat production. About twenty percentages of caloric contents in amino acids are consumed throughout the metabolic pathway, which differs from those of glucose and fatty acids (0\% - 5\%) [28]. In agreement with such differences among macronutrients in energy consumption through metabolic pathways, attenuation of hypothermia by intravenous infusion of amino acids mixture, but not by glucose and lipid, is also effective in an anesthetized rodent model.

\section{Mechanism for Preventing Hypothermia}

Similar with conscious rats, intravenous amino acids infusion clearly elevates protein synthetic rates in skeletal muscle accounting for a major proportion of the body protein synthesis [29]. These findings imply a subsequent production 
of heat due to greater energy consumption in skeletal muscle. The increase of muscular protein synthesis in anesthetized rats given amino acids is characterized by a marked elevation in plasma insulin concentrations. Most probably, this initiates phosphorylation of several translation initiation factors. Those factors are required for the stimulation of protein synthesis, through protein kinase $B$ and mammalian target of rapamycin [30]. The elevated plasma insulin levels under anesthetized state are features common to an animal model and human beings. Intriguingly, not only phosphorylation of these signaling transduction components and translation initiation factors but also amino acid-stimulated increase in oxygen consumption and core temperature is clearly cancelled by inhibiting the amino acid-induced elevation of plasma insulin by a pancreatic hormone inhibitor, somatostatin [31]. In terms of amino acids oxidation, intravenous infusion of amino acid boosts degradation of myofibrillarprotein [32]. This phenomenon could be the result of increased muscle protein turnover due to rapid infusion of amino acids. In that case both degradation and anabolism should be approximately equal. Interestingly, core temperature of anesthetized and conscious rats well correlates with plasma 3-methylhistidine, a marker of myofibrillar protein breakdown [32]. It is described that glucose infusion clearly inhibits degradation of myofibrillar protein through down-regulation of ubiquitin proteasome genes expression in rats [33]. However, it is still not clear how amino acids regulate the system and hence promote the myofibrillar protein degradation. The elevation in both synthesis and degradation rate of amino acids in the skeletal muscle provide collateral evidence of the critical role of elevated turnover in muscular protein metabolism, well known to generate heat. During anesthesia, when thermoregulation is impaired and the central inhibitory pathway in metabolism is depressed, the heat production in this process is increased compared to the awake state [4]. Another finding suggesting a key role of skeletal muscle as an organ for thermogenesis, was that infusion of amino acid mixture showed no effect on hypothermia in a rat model of skeletal muscle atrophy [34]. Moreover, in patients, splanchnic tissues did not change their proportion of the metabolism during amino acid infusion in the anesthesia and surgery period, whereas the extra-splanchnic metabolism was markedly enhanced [35]. In this aspect, skeletal muscles are able to accommodate a large protein turnover. Studies in patients with cervical spine ruptures and muscular atrophy showed increase postprandial plasma insulin levels [36]. Furthermore, intravenous infusion of amino acid mixture significantly elevates the thermoregulatory threshold for cold-defensive responses such as vascular contraction and shivering in both anesthetized and conscious human subjects [37]. All these findings intrigue linkage responses between central nervous system and muscular protein metabolism. Accumulation of heat in the body by infusion of amino acids, the most efficient macronutrient for protein synthesis, signifies the increase in both the order of biological molecules and disorder causing heat generation. We postulate the mechanisms of heat accumulation by amino acids (Figure 1). 


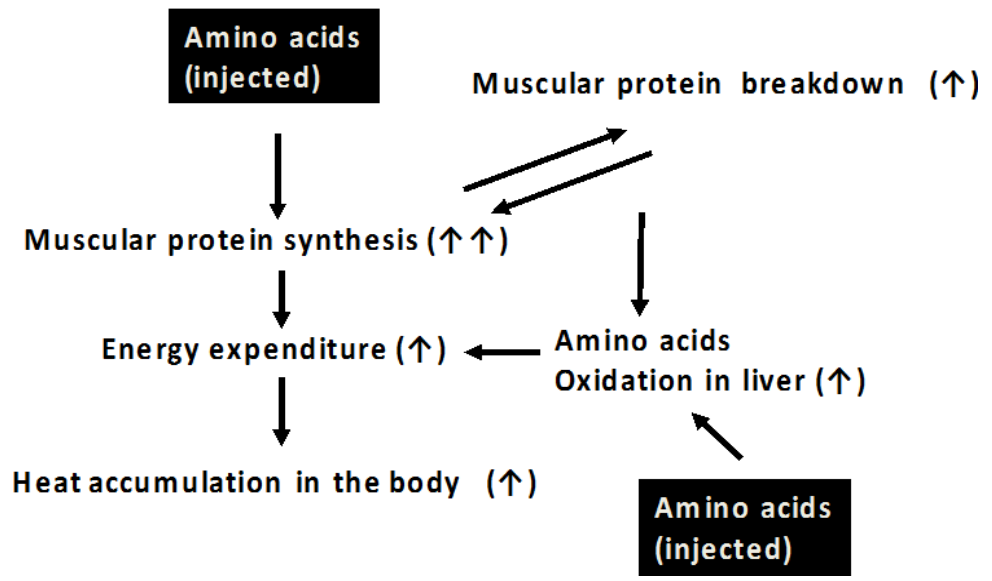

Figure 1. Amino acids infused in the body stimulate both protein synthesis and breakdown in the skeletal muscle and oxidation of amino acids in the liver, resulting in further increases in not only oxidation of amino acids in liver but also provision of building blocks for protein synthesis. All reactions require larger amounts of energy compared to glucose or lipid metabolism, leading to accumulate heat in the body.

\section{Nutritional Management during Perioperative Period}

Anesthesiologists have increased interest in nutritional management during perioperative period, however it is difficult to evaluate. It is well established that glucose is necessary for biological activity even during general anesthesia. The central nervous system, red blood cells and kidney medulla require only glucose as energy source. The brain consumes around $120 \mathrm{~g}$ of glucose a day for around $70 \mathrm{~kg}$ of patients, and $200 \mathrm{~g}$ of glucose is required except muscle exercise. Glucose is stored as glycogen in the body, but the total amount of glycogen is not sufficient for basal metabolism for one day. Shortage of glucose induces gluconeogenesis mainly in the liver [38]. Around $90 \%$ of gluconeogenesis uses amino acids as raw materials, and glycerol is used for the remaining around $10 \%$ of gluconeogenesis. There are various glucogenic amino acids, of which, after deamination, carbon structure is utilized for gluconeogenesis via pyruvate or oxaloacetate. Fatty acids are oxidated in mitochondria in the liver. Acceleration of ketogenesis in the liver causes ketonemia, which indicates shortage of glucose [39]. On the other hand, too much glucose is utilized for steatogenesis.

Yokoyama, one of authors of this article, reported that anesthetic management during surgery without glucose increases serum ketone bodies [40]. In patients undergoing orthopedic surgery, ketonemia is observed in a few hours from the start of surgery, but it was effectively avoided by $1.0 \%$ glucose infusion. Yamasaki et al. also reported similar results in patients undergoing head and neck surgery [41]. In addition, Mikura et al reported that infusion without glucose enhanced muscle protein breakdown in rat model [33]. Administration of amino acids and glucose in combination could be expected to contribute in nutritional management during the perioperative period. However, recently, a preliminary study has reported that combination of glucose and amino acid administration may offset the effect of amino acids in hypothermia prevention during 
anesthesia and surgery [42]. These results suggest that muscle protein breakdown might be required, along with protein synthesis, to attenuate hypothermia. It might be supposed that glucose and amino acids are not compatible with each other.

We reported that enteral administration of amino acids is also useful for preventing hypothermia in an animal model [43]. Oral administration is therefore also effective, but it may increase the risk of nausea and vomiting, since some amino acids may decrease stomach-emptying rate, most probably to avoid quick changes in serum nutrients. In addition, we found that orally administrated amino acids were badly tolerated due to bitter taste. Therefore, it is not possible to use this convenient way of amino acid intake preoperatively.

\section{Conclusion}

In conclusion, intravenous infusion of amino acids provides a useful and simple method for preventing hypothermia during anesthesia, by internal heat generation in the body, and it is well tolerated by the patients. However, we have to consider the principles of nutritional management for enhanced recovery. Further studies are required in this field. For administration of amino acids, ample room has been left for improving the administration timing, dose and route. In future, amino acids should be utilized not only to maintain body temperature but also to provide nutritional balance during perioperative period.

\section{Author Contributions}

Yokoyama T., Yamaoka Iand Hitosugi T. wrote the paper; Selldén E. supervised the manuscript.

\section{Supported by Conflict-of-Interest Statement}

Authors declare no conflict of interests for this article.

\section{References}

[1] Frank, S.M., Fleisher, L.A., Breslow, M.J., Higgins, M.S., Olson, K.F., Kelly, S. and Beattie, C. (1997) Perioperative Maintenance of Normothermia Reduces the Incidence of Morbid Cardiac Events. A Randomized Clinical Trial. JAMA, 277, 1127-1134. https://doi.org/10.1001/jama.1997.03540380041029

[2] Selldén, E. and Lindahl, S.G. (1999) Amino Acid-Induced Thermogenesis Reduces Hypothermia during Anesthesia and Shortens Hospital Stay. Anesthesia \& Analgesia, 89, 1551-1556. https://doi.org/10.1213/00000539-199912000-00045

[3] Beilman, G.J., Blondet, J.J., Nelson, T.R., Nathens, A.B., Moore, F.A., Rhee, P., Puyana, J.C., Moore, E.E. and Cohn, S.M. (2009) Early Hypothermia in Severely Injured Trauma Patients Is a Significant Risk Factor for Multiple Organ Dysfunction Syndrome But Not Mortality. Annals of Surgery, 249, 845-850. https://doi.org/10.1097/SLA.0b013e3181a41f6f

[4] Selldén, E., Brundin, T. and Wahren, J. (1994) Augmented Thermic Effect of Amino Acids under General Anaesthesia: A Mechanism Useful for Prevention of Anaesthesia-Induced Hypothermia. Clinical Science (Lond), 86, 611-618. 
https://doi.org/10.1042/cs0860611

[5] Ikeda, T., Ozaki, M., Sessler, D.I., Kazama, T., Ikeda, K. and Sato, S. (1999) Intraoperative Phenylephrine Infusion Decreases the Magnitude of Redistribution Hypothermia. Anesthesia \& Analgesia, 89, 462-465.

[6] Widman, J., Hammarqvist, F. and Selldén, E. (2002) Amino Acid Infusion Induces Thermogenesis and Reduces Blood Loss during Hip Arthroplasty under Spinal Anesthesia. Anesthesia \& Analgesia, 95, 1757-1762. https://doi.org/10.1097/00000539-200212000-00053

[7] Kasai, T., Nakajima, Y., Matsukawa, T., Ueno, H., Sunaguchi, M. and Mizobe, T. (2003) Effect of Preoperative Amino Acid Infusion on Thermoregulatory Response during Spinal Anaesthesia. British Journal of Anaesthesia, 90, 58-61.

https://doi.org/10.1093/bja/aeg020

[8] Sessler, D.I. (2010) Temperature Monitoring. In: Miller, R.D., Ed., Anesthesia, 7th Edition, Churchill Livingstone, Philadelphia, 1533-1556.

[9] Matsukawa, T., Sessler, D.I., Christensen, R., Ozaki, M. and Schroeder, M. (1995) Heat Flow and Distribution during Epidural Anesthesia. Anesthesiology, 83, 961-967. https://doi.org/10.1097/00000542-199511000-00008

[10] Sessler, D.I. (2000) Perioperative Heat Balance. Anesthesiology, 92, 578-596. https://doi.org/10.1097/00000542-200002000-00042

[11] Patel, N., Smith, C.E., Pinchak, A.C. and Hagen, J.F. (1996) Prospective, Randomized Comparison of the FlotemIie and Hotline Fluid Warmers in Anesthetized Adults. Journal of Clinical Anesthesia, 8, 307-316.

[12] Oddo, M., Frangos, S., Maloney-Wilensky, E., Andrew Kofke, W., Le Roux, P.D. and Levine, J.M. (2010) Effect of Shivering on Brain Tissue Oxygenation during Induced Normothermia in Patients with Severe Brain Injury. Neurocritical Care, 12, 10-16. https://doi.org/10.1007/s12028-009-9280-2

[13] Heier, T., Caldwell, J.E., Sessler, D.I. and Miller, R.D. (1991) Mild Intraoperative Hypothermia Increases Duration of Action and Spontaneous Recovery of Vecuronium Blockade during Nitrous Oxide-Isoflurane Anesthesia in Humans. Anesthesiology, 74, 815-819. https://doi.org/10.1097/00000542-199105000-00003

[14] Schmied, H., Kurz, A., Sessler, D.I., Kozek, S. and Reiter, A. (1996) Mild Hypothermia Increases Blood Loss and Transfusion Requirements during Total Hip Arthroplasty. The Lancet, 347, 289-292.

[15] Rajagopalan, S., Mascha, E., Na, J. and Sessler, D.I. (2008) The Effects of Mild Perioperative Hypothermia on Blood Loss and Transfusion Requirement. Anesthesiology, 108, 71-77. https://doi.org/10.1097/01.anes.0000296719.73450.52

[16] Wolberg, A.S., Meng, Z.H., Monroe, D.M. and Hoffman, M.A. (2004) Systematic Evaluation of the Effect of Temperature on Coagulation Enzyme Activity and Platelet function. Journal of Trauma, 56, 1221-1228. https://doi.org/10.1097/01.TA.0000064328.97941.FC

[17] Kurz, A., Sessler, D.I. and Lenhardt, R. (1996) Perioperative Normothermia to Reduce the Incidence of Surgical-Wound Infection and Shorten Hospitalization. Study of Wound Infection and Temperature Group. The New England Journal of Medicine, 334, 1209-1215. https://doi.org/10.1056/NEJM199605093341901

[18] Melling, A.C., Ali, B., Scott, E.M. and Leaper, D.J. (2001) Effects of Preoperative Warming on the Incidence of Wound Infection after Clean Surgery: A Randomised Controlled Trial. The Lancet, 358, 876-880.

[19] Bush, H.L., Hydo, L.J., Fischer, E., Fantini, G.A., Silane, M.F. and Barie, P.S. (1995) 
Hypothermia during Elective Abdominal Aortic Aneurysm Repair: The High Price of Avoidable Morbidity. Journal of Vascular Surgery, 21, 392-400.

[20] Busto, R., Dietrich, W.D., Globus, M.Y., Valdés, I., Scheinberg, P. and Ginsberg, M.D. (1987) Small Differences in Intraischemic Brain Temperature Critically Determine the Extent of Ischemic Neuronal Injury. Journal of Cerebral Blood Flow \& Metabolism, 7, 729-738. https://doi.org/10.1038/jcbfm.1987.127

[21] Cook, D.J., Orszulak, T.A. and Daly, R.C. (1998) Minimum Hematocrit at Differing Cardiopulmonary Bypass Temperatures in Dogs. Circulation, 98, 170-174.

[22] Al-Hashimi, S., Zaman, M., Waterworth, P. and Bilal, H. (2013) Does the Use of Thiopental Provide Added Cerebral Protection during Deep Hypothermic Circulatory Arrest? Interactive Cardio Vascular and Thoracic Surgery, 17, 392-397. https://doi.org/10.1093/icvts/ivt184

[23] Siddik-Sayyid, S.M., Abdallah, F.W. and Dahrouj, G.B. (2008) Thermal Burns in Three Neonates Associated with Intraoperative Use of Bair Hugger Warming Devices. Pediatric Anesthesia, 18, 337-339. https://doi.org/10.1111/j.1460-9592.2008.02474.x

[24] Albrecht, M., Gauthier, R.L., Belani, K., Litchy, M. and Leaper, D. (2011) Forced-Air Warming Blowers: An Evaluation of Filtration Adequacy and Airborne Contamination Emissions in the Operating Room. American Journal of Infection Control, 39, 321-328.

[25] Mizobe, T., Nakajima, Y., Ueno, H. and Sessler, D.I. (2006) Fructose Administration Increases Intraoperative Core Temperature by Augmenting Both Metabolic Rate and the Vasoconstriction Threshold. Anesthesiology, 104, 1124-1130. https://doi.org/10.1097/00000542-200606000-00005

[26] Woods, H.F. and Alberti, K.G. (1972) Dangers of Intravenous Fructose. The Lancet, 2, 1354-1357.

[27] Selldén, E., Bränström, R. and Brundin, T. (1996) Preoperative Infusion of Amino Acids Prevents Postoperative Hypothermia. British Journal of Anaesthesia, 76, 227-234. https://doi.org/10.1093/bja/76.2.227

[28] Flatt, J.P. (1978) The Biochemistry of Energy Expenditure. In: Bray, G., Ed., Recent Advances in Obesity Research, Newman, London, Vol. 2, Chapter 22, 211-228.

[29] Yamaoka, I., Doi, M., Nakayama, M., Ozeki, A., Mochizuki, S., Sugahara, K. and Yoshizawa, F. (2006) Intravenous Administration of Amino Acids during Anesthesia Stimulates Muscle Protein Synthesis and Heat Accumulation in the Body. American Journal of Physiology, 290, E882-E888. https://doi.org/10.1152/ajpendo.00333.2005

[30] Shah, O.J., Anthony, J.C., Kimball, S.R. and Jefferson, L.S. (2000) 4E-BP1 and S6K1: Translational Integration Sites for Nutritional and Hormonal Information in Muscle. American Journal of Physiology-Endocrinology and Metabolism, 279, E715-E729.

[31] Yamaoka, I., Doi, M., Kawano, Y., Nakayama, M., Watanabe, Y., Oba, K., Sugahara, K. and Yoshizawa, F. (2009) Insulin Mediates the Linkage Acceleration of Muscle Protein Synthesis, Thermogenesis, and Heat Storage by Amino Acids. Biochemical and Biophysical Research Communications, 386, 252-256.

[32] Yamaoka, I., Mikura, M., Nishimura, M., Doi, M., Kawano, Y. and Nakayama, M. (2008) Enhancement of Myofibrillar Proteolysis Following Infusion of Amino Acid Mixture Correlates Positively with Elevation of Core Body Temperature in Rats. Journal of Nutritional Science and Vitaminology, 54, 467-474. https://doi.org/10.3177/jnsv.54.467 
[33] Mikura, M., Yamaoka, I., Doi, M., Kawano, Y., Nakayama, M., Nakao, R., Hirasaka, K., Okumura, Y. and Nikawa, T. (2009) Glucose Infusion Suppresses Surgery-Induced Muscle Protein Breakdown by Inhibiting Ubiquitin-Proteasome Pathway in Rats. Anesthesiology, 110, 81-88. https://doi.org/10.1097/ALN.0b013e318190b6c1

[34] Kanazawa, M., Ando, S., Tsuda, M. and Suzuki, T. (2010) The Effect of Amino Acid Infusion on Anesthesia-Induced Hypothermia in Muscle Atrophy Model Rats. Journal of Nutritional Science and Vitaminology, 56, 117-122. https://doi.org/10.3177/jnsv.56.117

[35] Selldén, E., Bränström, R. and Brundin, T. (1996) Augmented Thermic Effect of Amino Acids under General Anaesthesia Occurs Predominantly in Extra-Splanchnic Tissues. Clinical Science, 91, 431-439. https://doi.org/10.1042/cs0910431

[36] Aksnes, A.K., Brundin, T., Hjeltnes, N., Maehlum, S. and Wahren, J. (1993) Meal-Induced Rise in Resting Energy Expenditure in Patients with Complete Cervical Spinal Cord Lesions. Paraplegia, 31, 462-472. https://doi.org/10.1038/sc.1993.75

[37] Nakajima, Y., Takamata, A., Matsukawa, T., Sessler, D.I., Kitamura, Y., Ueno, H., Tanaka, Y. and Mizobe, T. (2004) Effect of Amino Acid Infusion on Central Thermoregulatory Control in Humans. Anesthesiology, 100, 634-639. https://doi.org/10.1097/00000542-200403000-00025

[38] Rothman, D.L., Magnusson, I., Katz, L.D., Shulman, R.G. and Shulman, G.I. (1991) Quantitation of Hepatic Glycogenolysis and Gluconeogenesis in Fasting Humans with 13C NMR. Science, 254, 573-576. https://doi.org/10.1126/science.1948033

[39] Botham, K.M. (2009) Chapter 22 Oxidation of Fatty Acids: Ketogenesis. 28th Edition, Harper's Illustrated Biochemistry, Lange Medical Book, New York.

[40] Yokoyama, T., Suwa, K., Yamasaki, F., Yokoyama, R., Yamashita, K. and Sellden, E. (2008) Intraoperative Infusion of Acetated Ringer Solution Containing Glucose and Ionized Magnesium Reduces Ketogenesis and Maintains Serum Magnesium. Asia Pacific Journal of Clinical Nutrition, 17, 525-529.

[41] Yamasaki, K., Inagaki, Y., Mochida, S., Funaki, K., Takahashi, S. and Sakamoto, S. (2010) Effect of Intraoperative Acetated Ringer's Solution with 1\% Glucose on Glucose and Protein Metabolism. Journal of Anesthesia, 24, 426-431. https://doi.org/10.1007/s00540-010-0926-1

[42] Fujita, Y., Tokunaga, C., Yamaguchi, S., Nakamura, K., Horiguchi, Y., Kaneko, M. and Iwakura, T. (2014) Effect of Intraoperative Amino Acids with or without Glucose Infusion on Body Temperature, Insulin, and Blood Glucose Levels in Patients Undergoing Laparoscopic Colectomy: A Preliminary Report. Acta Anaesthesiologica Taiwanica, 52, 101-106.

[43] Imoto, A., Yokoyama, T., Suwa, K., Yamasaki, F., Yatabe, T., Yokoyama, R., Yamashita, K. and Selldén, E. (2010) Bolus Oral or Continuous Intestinal Amino Acids Reduce Hypothermia during Anesthesia in Rats. Journal of Nutritional Science and Vitaminology, 56, 104-108. https://doi.org/10.3177/jnsv.56.104 
Submit or recommend next manuscript to SCIRP and we will provide best service for you:

Accepting pre-submission inquiries through Email, Facebook, LinkedIn, Twitter, etc. A wide selection of journals (inclusive of 9 subjects, more than 200 journals)

Providing 24-hour high-quality service

User-friendly online submission system

Fair and swift peer-review system

Efficient typesetting and proofreading procedure

Display of the result of downloads and visits, as well as the number of cited articles Maximum dissemination of your research work

Submit your manuscript at: http://papersubmission.scirp.org/

Or contact ojanes@scirp.org 